\title{
CAPTURA, AISLACIÓN Y EVALUACIÓN DEL CRECIMIENTO DE MATERIAL FÚNGICO DE LA REGIÓN DE ÑUBLE PARA SU INCORPORACIÓN AL BANCO DE HONGOS COMESTIBLES DEL INSTITUTO FORESTAL
}

Chung, Patricio ${ }^{6}$

\section{RESUMEN}

Es de amplio conocimiento que los bosques no solo producen madera, sino que también una diversidad de otros productos, conocidos como productos forestales no madereros (PFNM), con frecuencia de sorprendente e insospechada importancia en el ámbito económico, alimentario y cultural entre la población que los habitan.

Los hongos silvestres comestibles presentes en los bosques de Chile constituyen un recurso valioso, cuyo comercio adquiere cada vez mayor importancia. No obstante, su producción natural bajo diferentes ambientes, como son el bosque y las praderas, es variable, de modo que el interés por obtener una producción alta y estable han motivado iniciativas para cultivarlos bajo diferentes estrategias de producción, ya sea mediante el establecimiento de cultivos en condiciones controladas o plantaciones con plantas inoculadas con hongos micorrícicos comestibles de alto valor.

Las diferentes estrategias de crecimiento en ambientes naturales de cada especie fúngica comestible y el interés por consumir productos orgánicos con características de alimento funcional, constituyen una ventajosa oportunidad para implementar líneas de investigación y desarrollo innovativo, que conjuguen aspectos como la conservación de estas especies, la recuperación y enriquecimiento de los bosques y la generación de productos intermedios de alto valor económico, ecológico y social, como son los hongos micorrícicos comestibles.

Dentro de las líneas de trabajo del Instituto Forestal en esta materia, se ha seguido potenciando el banco de hongos comestibles creado en el año 2015. Esto mediante colectas de especies y cepas de hongos silvestres comestibles asociados a bosques nativos, a bosques plantados y también a praderas en las diferentes regiones de Chile, con el propósito de constituir un banco que abra nuevas líneas de trabajo orientadas a definir protocolos que lleven a una producción sostenida de hongos comestibles tratando principalmente de valorizar sus funciones ecológicas y socioeconómicas. Dentro de este quehacer está la de investigar los parámetros que rigen su desarrollo. Bajo esta premisa, el presente trabajo evalúa el efecto de los medios PDA, MMN y BAF en el crecimiento in vitro de 52 cepas de diferentes especies silvestres comestibles, colectadas desde bosques nativos y plantaciones en la región de Ñuble.

Palabras clave: PFNM, Bosque nativo, Plantaciones Forestales, Hongos silvestres comestibles.

\footnotetext{
${ }^{6}$ Investigador Instituto Forestal, Chile. pchung@infor.cl
} 


\section{SUMMARY}

It is widely known that forests not only produce wood, but also a variety of non-wood forest products (NWFP), often of surprising and unsuspected economic, food and cultural importance among the population that inhabits them.

Edible wild mushrooms found in the forests of Chile are a valuable resource, the trade of which is becoming increasingly important. However, their natural production under different environments such as forests and grasslands is variable, so that the interest in obtaining a high and stable production has motivated initiatives to cultivate them under different production strategies, either through the establishment of crops in controlled conditions or plantations with plants inoculated with high-value edible mycorrhizal fungi.

The different growth strategies in natural environments of each edible fungal species and the interest in consuming organic products with functional food characteristics, constitute an advantageous opportunity to implement lines of innovative research and development, which combine aspects such as the conservation of these species, the recovery and enrichment of forests and the generation of intermediate products of high economic, ecological and social value, such as edible mycorrhizal fungi.

Within the lines of work of the Forest Institute in this matter, the edible mushroom bank created in 2015 has continued to be strengthened. This through collections of species and strains of wild edible fungi associated with native forests, planted forests as well as grasslands in the different regions of Chile, in order to establish a bank that opens new lines of work aimed at defining protocols that lead to a sustained production of edible mushrooms, mainly trying to value their ecological and socioeconomic functions. Within this task is to investigate the parameters that govern its development. Under this premise, the present work evaluates the effect of PDA, MMN and BAF media on the in vitro growth of 52 strains of different edible wild species, collected from native forests and plantations in the Ñuble Region.

Key words: NWFP, Native Forests, Planted forests, Edible Wild Mushrooms 


\section{INTRODUCCIÓN}

El reino de los hongos está representado por una gran diversidad de especies la que en la casi generalidad de los casos ha pasado inadvertida al momento de emprender alguna acción sobre los ecosistemas forestales. Sin embargo, en la actualidad se reconoce su importante rol ecológico al contribuir a la mantención de la estabilidad de los ecosistemas boscosos. A su vez, este cumple también un rol económico, alimentario y social, a través de los hongos silvestres comestibles, un importante recurso para la población que aloja dentro de los bosques o están cercanos a ellos y que muchas veces se desarrollan en parte en base a su comercio y/o autoconsumo para alimentación.

El uso de hongos en la dieta de los seres humanos ha prevalecido debido a su sabor, textura única y a su importante aporte nutricional, la que junto a sus propiedades terapéuticas los convierten en un excelente alimento funcional.

Actualmente, la recolección de hongos silvestres comestibles se ha convertido en muchos sectores del país en un importante motor generador de ingresos en el medio rural debido a que este recurso puede generar un flujo de ingresos adicionales en gran parte del año. Además, el conocimiento ancestral que posee la población local de especies comestibles características de cada zona con bosque nativo, como son las de los géneros Cyttaria, Ramaria, Morchella, Butyriboletus, entre otros; ha generado una serie de iniciativas culturales lo que les ha permitido identificarse con este recurso micológico y otorgarles a estas localidades un sentido de pertenencia, de identidad y de calidad territorial. Se suma a este recurso otros hongos comestibles de los géneros Suillus y Lactarius procedentes de las plantaciones de pino, con especies muy importantes desde el punto de vista de las exportaciones realizadas por décadas a países principalmente europeos.

La producción de hongos comestibles en bosques, matorrales y praderas constituye una de las principales riquezas forestales, sin embargo, al mencionar los productos forestales, se piensa exclusivamente en la madera, en circunstancias que los productos forestales no madereros, particularmente los hongos comestibles, ofrecen también una interesante alternativa productiva. Estos puede generar una rentabilidad incluso superior a la de cualquier otro producto forestal, sea madera, corteza o frutos, sobre todo si existen sitios en que la irregularidad climática y la degradación de los suelos no permite un rendimiento maderero elevado, tal como ocurre en muchos bosques naturales en Chile.

Para alcanzar a obtener ingresos por el uso maderero de los bosques se requieren lapsos de tiempo bastante largos, lo que genera un desarraigo entre el bosque y la comunidad. El poder lograr que la población rural se identifique con el bosque, ayudará a solucionar algunos problemas como la ocurrencia de incendios y el despoblamiento rural, entre otros; además, el involucrar a la comunidad en el manejo y cuidado del bosque permite que esta lo sienta como algo que es necesario conservar. Esta identidad solo se puede lograr si la comunidad rural ve en el bosque algo productivo y que le reporte beneficios periódicamente.

Los hongos silvestres comestibles en su mayor parte realizan simbiosis con árboles forestales, siendo esto muy benéfico desde el punto de vista ecológico como también en la generación de productos, que en algunos casos pueden alcanzan precios interesantes en los mercados nacionales e internacionales convirtiéndose en un elemento valioso, cuyo comercio adquiere cada día mayor importancia. Sin embargo, su producción depende del tipo de hábitat, presentando además una marcada estacionalidad y un impredecible nivel de producción anual, lo que, unido a la intervención del ser humano en los hábitats naturales donde se producen, determinan que su abundancia natural en el bosque sea variable. Estos factores, junto a una demanda creciente han comenzado a generar una gran presión sobre el recurso micológico lo que 
hace reflexionar sobre el peligro que se cierne sobre algunas especies fúngicas, sobre todo las nativas. Como una solución a este problema de sustentabilidad del recurso y al interés por obtener una producción alta y estable, se han abordado iniciativas de investigación para cultivarlos dentro o fuera de los bosques mediante diferentes técnicas de cultivo.

Estos hongos comestibles proveniente de bosques y praderas por sí solos ya son importantes para la generación de ingresos estacionales y también como fuente de alimentos para los habitantes de zonas rurales, por cuanto constituyen un producto altamente proteico, con abundante fibra, vitaminas, minerales y escasa cantidad de grasas.

En general, la producción de hongos no suele ser considerada como un objetivo productivo al momento de establecer plantaciones forestales. Esto se debe a la dificultad que involucra cuantificar su producción y su efecto sobre la rentabilidad final para el propietario. Para superar estas dificultades se requieren estudios específicos, así como también crear pautas de gestión de los bosques que permitan compatibilizar el aprovechamiento de los hongos, con las restantes finalidades del bosque.

Uno de los factores que explica la relativamente baja producción de cuerpos frutales de hongos comestibles en los bosques naturales y plantaciones forestales, es el empleo de técnicas de establecimiento y/o manejo inadecuadas, que afectan negativamente las condiciones ambientales al interior de los bosques, limitando la producción de hongos durante el desarrollo de las masas boscosas. De igual forma, la falta de información y conocimientos respecto de los hongos comestibles y sus asociaciones con especies forestales, limita el aprovechamiento de estos organismos y también de las ventajas productivas que estos confieren a las plantas.

Para el caso de los hongos micorrícicos comestibles, la relación de simbiosis establecida entre hongos y especies forestales constituye una ventajosa oportunidad para implementar líneas de investigación y desarrollo innovativas, que conjuguen la recuperación de suelos degradados, la restauración y enriquecimiento del bosque nativo y el mejor desempeño de las plantaciones, con la generación de productos intermedios de alto valor económico, ecológico y social, como son los hongos micorrícicos comestibles.

La iniciativa, enmarcada en el área de Diversificación Forestal de INFOR, dentro de la cual se inserta la línea de Productos Forestales no Madereros, tiene como objetivo realizar una prospección y colecta de especies y cepas de hongos silvestres comestibles asociados a bosques de Nothofagus spp y plantaciones de Pinus radiata. Una vez obtenido dicho material, se deberán establecer investigaciones en torno a la búsqueda de protocolos que ayuden a obtener una producción sostenida de hongos silvestres comestibles en ambientes silvestres.

Además, con la constitución de un reservorio de cepas de hongos comestibles se pretende generar una ventana hacia el conocimiento de la biodiversidad fúngica regional ante la sociedad y ante la comunidad científica. Se trata de una herramienta que podrá entregar conocimiento de una parte de la flora fúngica nacional, la que podrá ser difundida en el ámbito regional, nacional e internacional. Sin embargo, esto requerirá de un apoyo técnico permanente para el mantenimiento y conservación del material a largo plazo para futuras acciones que se lleven a cabo.

Se agrega también que, en la actualidad, el estudio de muchos microorganismos y de sus metabolitos, entre los cuales se encuentran los hongos, se ha transformado en un tema de gran importancia si se toma en cuenta un sinnúmero de aplicaciones que se les han encontrado, con aportes significativos para el hombre. Por ello, es de suma importancia desarrollar metodologías 
que permitan la adecuada conservación de los microorganismos de tal manera que se pueda acceder a ellos de una manera rápida, sencilla y confiable.

Por último, la información generada respecto a su presencia en sitios diversos (suelo, clima, época de aparición, situación geográfica, vegetación asociada) permitirá una mejor comprensión del comportamiento de estos hongos, lo que ayudará a los futuros trabajos en conservación y uso sostenible del recurso micológico.

\section{REVISIÓN BIBLIOGRÁFICA}

Los bosques albergan diversos productos forestales no madereros (PFNM) que tienen una importancia económica, alimentaría y cultural entre la población que los habitan o se encuentran cercanas a ellos (Rodriguez et al., 2012). Los PFNM son "todos aquellos productos biológicos, excluida la madera, leña y carbón, que son extraídos de los bosques naturales para el uso humano" (Peters, 1996). Dentro de estos se encuentran los HSC los cuales podrían ser una alternativa en el manejo sustentable del bosque (FAO, 2008)

Catalán (2006) estima que los PFNM pueden constituir el 30 al $40 \%$ del uso comercial de un bosque. Su importancia radica en que constituyen una fuente de ingresos para sus recolectores y en que potencialmente pueden transformarse en la clave para el manejo sustentable de los bosques nativos.

La recolección periódica de productos del bosque representa un ingreso complementario en la economía de muchas familias rurales. La característica estacional de la producción permite mantener, en algunos hogares, una actividad casi continua que se reparte entre sucesivos productos, constituyendo además una gran oportunidad para valorizar el bosque nativo a través de la generación de actividades económicas alternativas, que permitan a los pequeños propietarios ocupar su excedente de mano de obra, obtener ingresos estables y diversificar su base productiva (Tacón y Palma, 2005).

Aunque no existen registros del mercado interno de estos productos, que permitan evaluar su importancia económica en el ámbito nacional, se dispone de estadísticas de comercialización para la mayor parte de los productos de exportación. La mayor demanda para estos productos se concentra en los países desarrollados del hemisferio norte, los cuales importan principalmente materias primas para la industria farmacéutica, cosmética y alimentaria. El mercado internacional de los PFNM es creciente y con amplias posibilidades para el futuro (INFOR, 2004; Tacón y Palma, 2005).

A pesar del sorprendente y atractivo negocio que resulta ser la exportación de PFNM, no se encuentra exento de problemas, los elevados precios de compra del producto han generado una enorme presión por su extracción, lo que ha significado la desaparición de muchas de sus poblaciones naturales, debido principalmente a sus métodos de extracción (Tacón y Palma, 2005).

Este es el caso de algunas especies de hongos silvestres comestibles presente en los bosques nativos chilenos, caracterizados por presentar una sobreutilización del recurso, implicando con ello una disminución de la calidad y cantidad de los ejemplares que lo componen. Los sistemas de explotación utilizados se han limitado solo a extraer la totalidad de los ejemplares sin claras posibilidades de un aprovechamiento sostenible en el tiempo, llegando incluso a la destrucción de los bosques que los albergan, como es el caso del hongo Cyttaria berteroi, especie catalogada como "en peligro". 
Entre las especies nativas más perjudicadas se encuentran especies como la Grifola gargal (gargal), Butyriboletus loyo (loyo), Cortinarius lebre (lebre u hongo liebre) y varias especies del género Ramaria (changle amarillo o rosado), Morchella (morchela, morilla) y Cyttaria (digüeñe, pinatra, Ilao-llao); cuyos cuerpos fructíferos son recolectados por habitantes de zonas rurales para su consumo y/o venta. Para muchos recolectores, los hongos nativos son uno de sus principales fuentes de ingresos, siendo un recurso cada vez más escaso y que posee una alta demanda por sus excelentes cualidades culinarias y un alto precio (Taller de Acción Cultural, 2003).

Las comunidades mapuches que habitan las zonas boscosas del país poseen un gran conocimiento de los hongos comestibles silvestres nativos y por muchos años estos se han convertido en un recurso muy valioso para su alimentación, cuya sabiduría relativa al reconocimiento de las distintas especies, lugares donde colectarlas y en qué época del año encontrarlas es aprendida o heredada de sus antepasados.

En base a estos antecedentes, la implementación de acciones que aumenten la presencia de las distintas especies de hongos comestibles en los bosques nativos, es necesaria para que la recolección no se transforme en un agente de degradación, sino que al contrario sea un incentivo para el manejo forestal sustentable y la conservación de los recursos.

Frente a este nuevo escenario, en los últimos años los productos forestales del bosque nativo han concentrado la atención de diversos profesionales, debido a la oportunidad que se presenta para la conservación de la biodiversidad, el desarrollo sustentable y por los altos niveles de comercialización que han alcanzado a escala global diversos productos derivados de ellos (Saavedra, 2004).

Existe un interés comercial por la diversificación debido a las crecientes perspectivas de nuevos sabores y texturas y a un mejor conocimiento de las funcionalidades de los componentes fúngicos moleculares (Honrubia, 2011). Entre la gran diversidad de hongos que existen en la naturaleza, una gran parte de ellos tiene aplicaciones en el área industrial, de los alimentos, de la medicina, entre otras. En este sentido, Boa (2005) menciona que en el mundo existen 1.097 especies de setas consideradas solo como comestibles, 1.069 consideradas como alimento y 470 especies consideradas medicinales. En tanto que en Chile existirían aproximadamente 53 especies de hongos silvestres comestibles (Valenzuela, 2003).

Para el caso de las plantaciones de pino, existen importantes especies de hongos comestibles que son colectadas y comercializadas a nivel nacional e internacional. Su presencia en estas masas vegetacionales comienza a los 4 años desde su establecimiento, incrementando su producción hasta los 12 años, siendo las especies fúngicas típicas, Suillus luteus, S. granulatus, $S$. bellini, Rhizopogon luteolus, $R$. roseolus y Lactarius deliciosus.

\section{MATERIAL Y MÉTODO}

El presente trabajo comprendió varias etapas, comenzando con la identificación de los hábitats naturales en donde se desarrollan los bosques de especies del género Nothofagus y las plantaciones de Pinus radiata dentro de los cuales se pudieran encontrar especímenes de hongos silvestres comestibles.

Un segundo punto a desarrollar fueron los trabajos de prospección y colecta de especímenes seguido de trabajos en laboratorio para la aislación bajo condiciones asépticas (in vitro) de cada ejemplar colectado. Por último, la realización de ensayos para la determinación preliminar de los medios de cultivo más aptos para el desarrollo de cada cepa que haya sido 
posible aislar, buscando el ingreso definitivo de nuevas cepas de especies de hongos comestibles de la región de Ñuble al banco de hongos del Instituto Forestal en Concepción.

\section{Identificación de Zonas de Prospección y Colecta}

La información utilizada para establecer las posibles áreas de prospección y colecta de especímenes de hongos comestibles dentro de la región de Ñuble se basó en la identificación de las zonas de crecimiento en las que se desarrollaban los bosques de las especies del género Nothofagus, como también de las plantaciones de Pinus radiata, en cuyas masas vegetacionales se ubican la mayoría de las especies de hongos comestibles, tanto nativos como exóticos.

Para la elaboración del mapa con la distribución del género Nothofagus para la región de Ñuble, se utilizó el "Catastro de los Recursos Vegetacionales Nativos de Chile" actualizado al año 2015 por la Corporación Nacional Forestal (CONAF, 2015). En el material indicado se identificaron las masas vegetacionales donde participa este género en base a criterios de dominancia de estas especies, dentro de cada masa vegetacional. En este mapa se ubicaron las masas vegetacionales con presencia de las especies raulí, roble, coihue, hualo, lenga y ñirre en condición de especies dominantes o codominantes.

En la confección del mapa de distribución de las plantaciones de Pinus radiata, se utilizó la información obtenida por el Instituto Forestal del Programa de Actualización Permanente de Plantaciones Forestales (INFOR, 2019). Para realizar esta tarea, se pudo contar con el apoyo del área de investigación Inventario Forestal Continuo de INFOR, sede Bío Bío.

\section{Ficha Descriptiva para Cada Cepa}

Para ayudar a describir algunos aspectos relacionados a características de sitio en el cual se estaban desarrollando los hongos colectados, se elaboró un formulario de terreno que recogió una breve descripción de aspectos que pudieran ser de importancia para el desarrollo de dichas fructificaciones. Dentro de los datos colectados, se contemplaron aspectos como ubicación geográfica, asociación vegetacional asociada, suelo, altitud, exposición, fecha, intervenciones silvícolas, recolector, entre otros antecedentes.

\section{Campaña de Terreno}

Para una mayor eficacia de las tareas de búsqueda de especímenes de hongos comestibles, estas se concentraron para el caso de los bosques de Nothofagus en sectores con mayor presencia de este género, es decir, las zonas de precordillera. Para el caso de los hongos en bosques de pino, su búsqueda se centró en las diferentes zonas de crecimiento predefinidas en el mapa de la región a prospectar, concentrándose en las zonas cercanas a la costa, áreas donde se concentran las mayores superficies de plantaciones con esta especie.

Si bien se identificaron las zonas vegetacionales en donde se desarrollaban Pinus radiata y Nothofagus spp, la colecta se desarrolló en base a las condiciones de humedad existentes en la región de prospección, las cuales presentaron gran deficiencia en precipitaciones, con montos insuficientes para la aparición de varias especies de importancia.

En la zona a prospectar se pueden identificar dos épocas de cosecha que son los períodos de otoño y primavera, siendo los meses abril-junio y septiembre-noviembre, respectivamente. Sin embargo, los trabajos de recolección realizadas en la región a prospectar, para los períodos de primavera y otoño fueron bastante cortos debido a la escasez de precipitaciones. 
Las mayores fructificaciones ocurrieron en la época de invierno-primavera, período en el cual las precipitaciones se presentaron con mayor abundancia. Bajo estos resultados, se constató que las precipitaciones son un aspecto importante en la aparición de las diferentes especies de hongos comestibles silvestres de los bosques.

Es de mencionar que los períodos de aparición de las diferentes especies de hongos pueden variar de un año a otro, debido a que estos están muy ligados a factores climáticos. Los parámetros principales que se deben tener en cuenta son la temperatura y las precipitaciones, por lo que no es posible precisar una fecha de aparición y término de una producción fúngica determinada. Los cambios ambientales que se han producidos en los últimos años han empezado a modificar los tiempos en que los cuerpos fructíferos de los hongos aparecen, por lo que acontecimientos de sequía o de abundancia en precipitaciones pueden afectar la aparición y cantidad.

De acuerdo a lo anterior, se comenzaron a realizar las salidas de prospección y colecta un par de semanas después de que se produjeron las primeras lluvias otoñales o primaverales, las cuales deberían ser abundantes de tal forma de obtener una conveniente infiltración bajo la capa vegetal y especialmente en el primer horizonte del suelo, aspectos que, junto con la temperatura, permitirían que los hongos pudieran activar sus mecanismos de fructificación.

Por último, es de mencionar que una de las grandes desventajas en realizar los trabajos de prospección y colecta en esta región, fueron las distancias entre los diferentes sectores a prospectar, ahondando más esta dificultad la distancia de estos sectores con el lugar de procesamiento de los especímenes, el cual se encuentra en Concepción. Se agregan, además, la atomización de las áreas de bosque nativo en esta región por el grado de deterioro por el uso del suelo y la degradación misma de estos bosques, repartiéndose en pequeños bosquetes aislados y esparcidos a grandes distancias dentro de propiedades privadas que limitan la búsqueda y la entrada a estas zonas.

Por lo dificultoso de la prospección y recolección en áreas del bosque nativo de la región objetivo, los trabajos no se limitaron solamente a esta, sino que a otras en las que se pudieran buscar y rescatar especímenes y cepas que aún no han sido colectados en anteriores trabajos, permitiendo ir cubriendo zonas del bosque nativo no exploradas y así ir completando el banco de cepas.

\section{Colecta y Captura de Información}

Para cada muestra colectada se tomaron diversos datos en terreno para caracterizar el sitio de crecimiento del espécimen capturado. Para ello se utilizó una ficha previamente confeccionada, tomando los datos necesarios para caracterizar ambientalmente la cepa colectada. Para ello se contó con los formularios respectivos y un GPS para establecer la ubicación geográfica.

Sin embargo, muchas colectas fueron facilitadas por los propios lugareños de las áreas a prospectar, resguardando así en secreto los lugares de aparición de hongos de importancia como es Grifola gargal, por lo cual para esta especie no se cuenta con una descripción detallada de los lugares de colecta.

Para el transporte del material de colecta, cada muestra colectada fue puesta en una bolsa de papel, previamente marcada con la fecha y la identificación respectiva de la muestra y colocada posteriormente en un contenedor plástico que en su interior contenía barras artificiales 
congeladas (ice pack) para mantener las muestras a una temperatura de $5^{\circ} \mathrm{C}$ hasta su arribo al laboratorio.

La colecta se realizó de acuerdo al siguiente protocolo:

a.- Selección priorizada de sitios de colecta en función de características climáticas favorables a la fructificación.

b.- Identificación preliminar de los hongos en terreno y captura de datos para la caracterización del lugar de muestreo.

c.- Extracción de cuerpos fructíferos y limpieza de los mismos con brocha o pincel grueso para eliminar partículas de suelo y materia orgánica.

d.- Embalaje de las muestras en bolsas de papel para permitir la respiración del hongo e impedir la acumulación de humedad, lo que induciría a un mayor deterioro de la muestra.

f.- Identificación de la bolsa con el número de la muestra colectada en terreno, lugar y fecha.

g.- Almacenaje en contenedor de aislapol o plástico con hielo o ice pack para su preservación durante el viaje.

h.- Transporte en forma rápida (no más de 2 días) al laboratorio para proceder a la aislación del micelio o esporas.

i.- Identificación final si fuese necesario, tanto del cuerpo frutal como del micelio aislado con el apoyo de un especialista en taxonomía fúngica.

\section{Aislación y Acondicionamiento de Cepas}

\section{- Codificación de Especímenes}

Para ordenar los especímenes colectados, aislados e incorporados al Cepario de Hongos Comestibles del Instituto Forestal, se utilizó una codificación que permitió vincular la información de terreno, los registros fotográficos y las diferentes cepas aisladas.

El código aplicado fue el siguiente:

\section{IFAABBCCC}

Donde:

IF: Instituto Forestal (Institución Colectora)

AA: Región de Chile

BB: Sector de Colecta

CCC: Número de la cepa

\section{- Preparación de Medios de Cultivo}

Para conseguir la aislación del material fúngico, se preparó un medio de cultivo que permitiera el desarrollo de los tejidos de los hongos.

En esta etapa se usó una modificación del medio Melin-Norkrans (MMN), que corresponde a un medio común para el crecimiento de hongos tanto saprófitos, como micorrícicos y parásitos (Marx, 1969). La formulación del medio MMN se muestra en el Cuadro $\mathrm{N}^{\circ} 1$. 
Cuadro $\mathrm{N}^{\circ} 1$

FORMULACIÓN DEL MEDIO MMN MODIFICADO

\begin{tabular}{|c|c|}
\hline Nutrientes & Cantidad \\
\hline \multicolumn{2}{|l|}{ Fuentes de carbohidratos } \\
\hline Extracto de Malta & $2 \mathrm{~g}$ \\
\hline D - Glucosa & $5 \mathrm{~g}$ \\
\hline \multicolumn{2}{|l|}{ Nutrientes Minerales } \\
\hline$\left(\mathrm{NH}_{4}\right)_{2} \mathrm{HPO}_{4}$ & $0,25 \mathrm{~g}$ \\
\hline $\mathrm{KH}_{2} \mathrm{PO}_{4}$ & $0,5 \mathrm{~g}$ \\
\hline $\mathrm{MgSO}_{4} \bullet 7 \mathrm{H}_{2} \mathrm{O}$ & $0,15 \mathrm{~g}$ \\
\hline $\mathrm{CaCl}_{2}$ & $0,05 \mathrm{~g}$ \\
\hline $\mathrm{FeCl}_{3}$ & 1,2 ml (sol. 1\%) \\
\hline $\mathrm{NaCl}$ & $0,025 \mathrm{~g}$ \\
\hline \multicolumn{2}{|l|}{ Vitaminas } \\
\hline Tiamina $\mathrm{HCl}$ & $100 \mu \mathrm{g}$ \\
\hline Agua Destilada & $1.000 \mathrm{ml}$ \\
\hline $\mathrm{pH}$ & 5,5 \\
\hline Agar & $15 \mathrm{~g}$ \\
\hline
\end{tabular}

Previo a la confección de los medios de cultivo, se realizó la desinfección de la cámara con alcohol al $70 \%$ y tratada con luz UV junto a las placas de Petri. El medio de cultivo fue preparado en frascos Erlenmeyer de 1 litro, adicionando los productos químicos, vitaminas, carbohidratos y agar correspondientes a la fórmula.

Se verificó el $\mathrm{pH}$ mediante un peachímetro, ajustándose este con $\mathrm{KOH}$ o $\mathrm{HCl}$, para subir o bajar el $\mathrm{pH}$, respectivamente. Cada medio fue esterilizado en autoclave a $121^{\circ} \mathrm{C}$ de temperatura, 1,2 atmósferas de presión y en un lapso de 20 minutos.

Terminada la esterilización de los medios, estos fueron llevados a la cámara de flujo laminar para ser vaciados en placas Petri. El vaciado del medio se realizó con una jeringa estéril con el medio a temperaturas sobre los $40^{\circ} \mathrm{C}$, para evitar la solidificación de este, agregando $20 \mathrm{ml}$ de medio a cada uno de las placas.

Finalizado el vaciado, se dejaron enfriar las placas Petri, visualizando en ellas la finalización de la condensación producto de la evaporación. Posteriormente, estas fueron guardadas o utilizadas inmediatamente. Este proceso se realizó bajo una cámara de flujo laminar para el trabajo dentro de un ambiente estéril (Figura $\mathrm{N}^{\circ} 1$ ). 


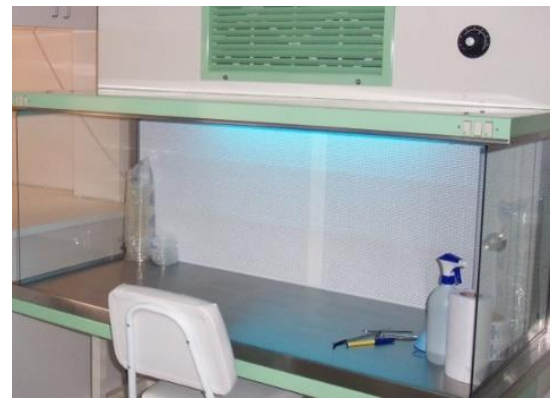

(a)

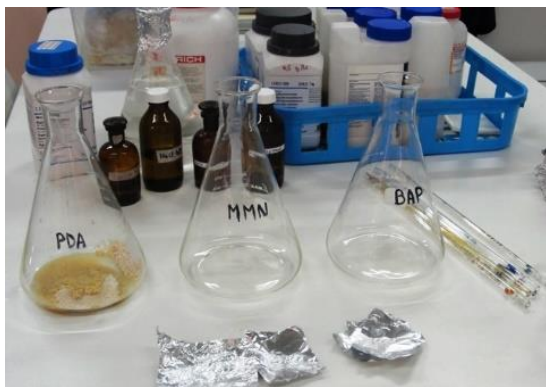

(c)

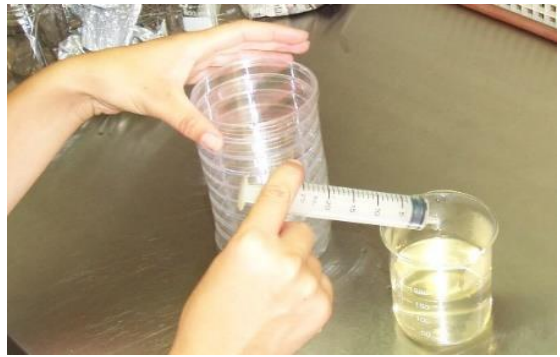

(e)

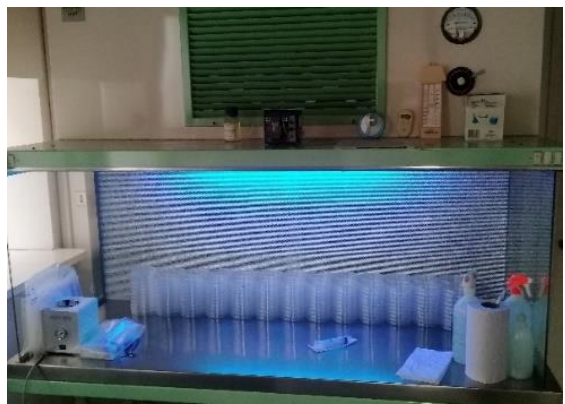

(b)

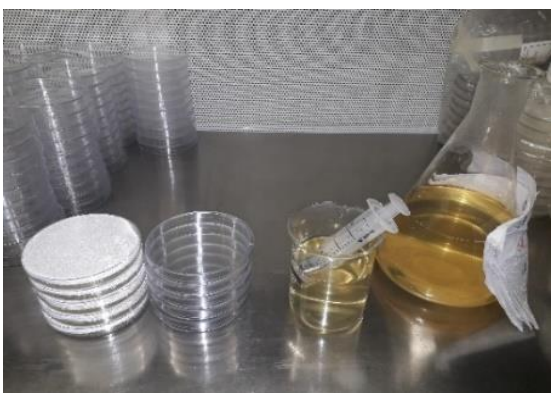

(d)

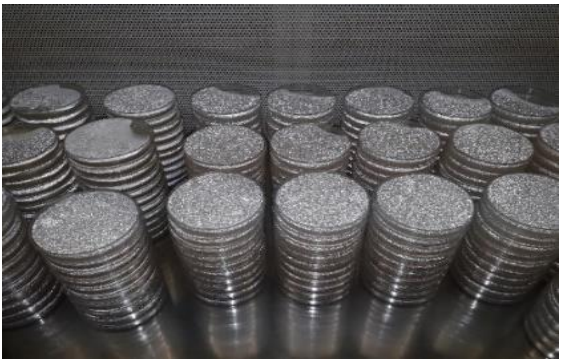

(f)

(a) Esterilización del interior de la cámara de flujo laminar con alcohol al 70\% y luz UV

(b) Preparación de placas Petri bajo cámara de flujo laminar en ambiente estéril

(c) Confección de medios de cultivo con elementos particulares de cada uno

(d) Medio esterilizado y vaciado de medio con jeringa estéril a placas Petri

(e) Vaciado de medios de cultivo en placas Petri estériles

(f) Placas Petri con medios de cultivo en etapa de secado

Figura $\mathrm{N}^{\circ} 1$

PREPARACIÓN DE MEDIOS DE CULTIVO 


\section{- $\quad$ Procedimientos de Aislación de Tejidos}

En la etapa de aislación, cada muestra colectada fue previamente registrada en laboratorio en base a una toma fotográfica (Anexo $\mathrm{N}^{\circ} 2$ ) y la asignación del código antes mencionado.

La inoculación de los medios se realizó bajo una cámara de flujo laminar, tomando un segmento de tejido del cuerpo fructífero del hongo. Para ello, se realizó la segmentación del hongo, dejando expuesto el tejido estéril presente en el interior, permitiendo así la extracción de pequeñas porciones de tejido, los cuales se colocaron sobre el medio de cultivo. Hecho este procedimiento, las placas de Petri se sellaron con papel parafilm, procediendo finalmente a marcar con el código de la cepa, medio de cultivo utilizado y la fecha de aislación. Posteriormente las placas de Petri se colocaron en un ambiente oscuro a $23^{\circ} \mathrm{C}$ de temperatura, para que se desarrolle y se verifique el crecimiento sin presencia de otros contaminantes, como bacterias $u$ otro hongo contaminante (Figura $\mathrm{N}^{\circ} 2$ ).

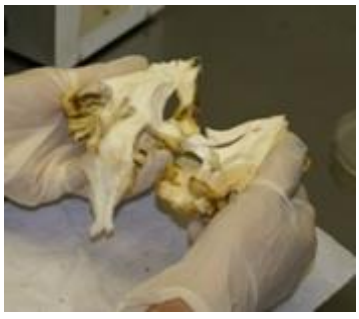

(a)

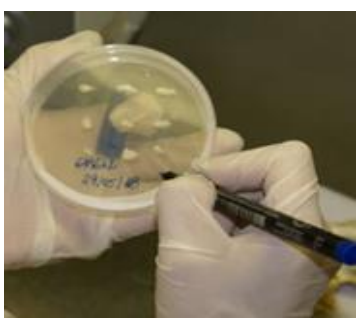

(d)

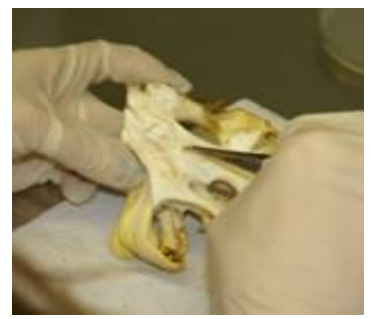

(b)

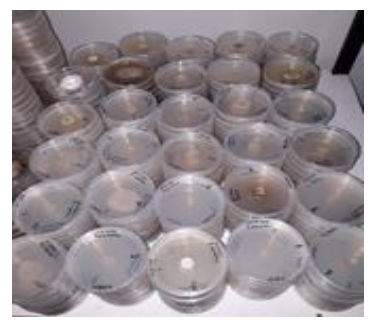

(e)

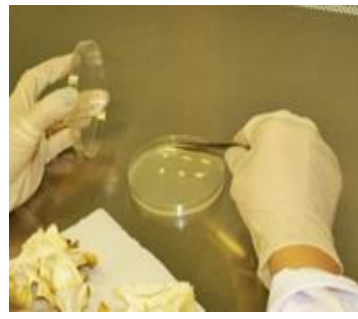

(c)

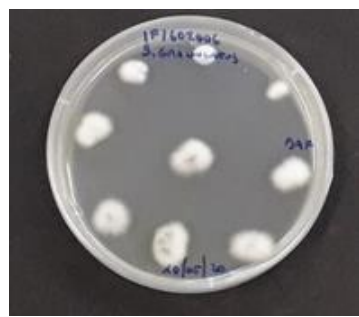

(f)

(a) Seccionado del cuerpo fructífero para exponer tejido estéril

(b) Extracción de tejido estéril para colocarlo en medio de cultivo

(c) Tejido miceliar del hongo en medio de cultivo estéril

(d) Tejido miceliar en placa Petri sellado con papel parafilm con código, medío de cultivo y fecha

(e) Placas Petri con tejido aislado en cámara de crecimiento a $23^{\circ} \mathrm{C}$ y en oscuridad

(f) Estado de desarrollo de tejido a los 30 días de su aislamiento, sin contaminación

Figura $\mathrm{N}^{\circ} 2$

AISLACIÓN DE TEJIDOS 
Para cada cepa aislada, se realizó un seguimiento para ver la evolución del crecimiento y la posible aparición de contaminantes como bacterias y otros hongos.

Ante la aparición de agentes contaminantes, se procedió a realizar subcultivos transfiriendo micelio limpio a medio fresco.

De esta forma, se logró la aislación definitiva de la mayoría de las cepas y con ello la obtención de una cantidad de material suficiente para el montaje de los ensayos para la selección de los medios de crecimiento apropiados para cada cepa.

\section{Determinación de Medios de Crecimiento}

Una vez establecida la aislación definitiva de la gran mayoría de las cepas colectadas, se estableció un ensayo para definir el mejor medio de crecimiento, en términos técnicos y económicos, entre tres alternativas que fueron evaluadas para cada cepa.

El ensayo se estableció en laboratorio, con condiciones ambientales de $23^{\circ} \mathrm{C}$ de temperatura y $55 \%$ de humedad de acuerdo a lo indicado por Santiago-Martínez et al. (2003).

Los medios utilizados fueron los sugeridos por Murrieta et al. (2013), quienes citando a varios investigadores, señalan que los medios más utilizados, ya sea para el aislamiento (medios sólidos) o la micorrización (medios líquidos), son el BAF (Biotina Aneurina Ácido Fólico) (Moser, 1960), MMN (Medio Melin-Norkrans), y PDA (Papa Dextrosa Agar) que varían de mayor a menor complejidad y costo (Cuadro $\mathrm{N}^{\circ} 2$ ).

Además, los mencionados autores indican que estos medios de cultivo han sido probados en otro tipo de especies y que se han obtenido diversos resultados respecto al éxito de crecimiento y desarrollo del micelio.

Los ensayos se montaron en placas Petri de vidrio, de $9 \mathrm{~cm}$ de diámetro por $1,5 \mathrm{~cm}$ de altura, previamente esterilizadas en autoclave a $1,2 \mathrm{~atm}$., a $120^{\circ} \mathrm{C}$ por 20 minutos. Los medios de cultivo utilizados en los ensayos se esterilizaron en frascos Erlenmeyer de $1 \mathrm{~L}$, dispuestos en una autoclave a $1,2 \mathrm{~atm}$ de presión, y $120^{\circ} \mathrm{C}$ por $20 \mathrm{~min}$.

El vaciado del medio a las placas Petri se realizó con jeringa desechable, trabajando bajo una cámara de flujo laminar previamente esterilizada con alcohol al $70 \%$ y baños de luz ultravioleta.

En cada placa Petri se depositaron $20 \mathrm{ml}$ de medio de cultivo, dejando enfriar posteriormente para su solidificación y verificando la eliminación del vapor de agua dentro de cada placa antes de su uso.

Para la inoculación de los medios de cultivo con cada una de las cepas a evaluar, se procedió a utilizar uno de dos tipos de sacabocados que permitían obtener círculos de micelio de $1,4 \mathrm{~cm}$ de diámetro a partir del crecimiento inicial en los trabajos de aislación.

La instalación de los ensayos se realizó bajo un ambiente estéril dado por una cámara de flujo laminar, dentro de la cual se realizó la inoculación de los medios de cultivo. Esta se instaló, utilizando los círculos de micelio obtenidos por los sacabocados y extraídos con un asa estéril para su ubicación en los medios de cultivo. 
Cuadro $\mathrm{N}^{\circ} 2$

FORMULACIÓN DE LOS MEDIOS DE CRECIMIENTO A EVALUAR

\begin{tabular}{|c|c|c|c|}
\hline \multirow{2}{*}{ Nutrientes } & \multicolumn{3}{|c|}{ Composición de Medios de Cultivo } \\
\hline & Medio MMN & Medio BAF & Medio PDA \\
\hline \multicolumn{4}{|l|}{ Fuentes de carbohidratos } \\
\hline Extracto de levadura & & $0,2 \mathrm{~g}$ & \\
\hline Extracto de papa & & & $4 \mathrm{~g}$ \\
\hline Extracto de Malta & $2 \mathrm{~g}$ & & \\
\hline Peptona & & $2 \mathrm{~g}$ & \\
\hline D - Glucosa & $10 \mathrm{~g}$ & $30 \mathrm{~g}$ & $20 \mathrm{~g}$ \\
\hline \multicolumn{4}{|l|}{ Nutrientes Minerales } \\
\hline$\left(\mathrm{NH}_{4}\right)_{2} \mathrm{HPO}_{4}$ & $0,25 \mathrm{~g}$ & & \\
\hline $\mathrm{FeCl}_{3} \bullet 6 \mathrm{H}_{2} \mathrm{O}$ & & $10 \mathrm{mg}$ & \\
\hline $\mathrm{ZnSO}_{4} \cdot 7 \mathrm{H}_{2} \mathrm{O}$ & & $1 \mathrm{mg}$ & \\
\hline $\mathrm{MnSO}_{4} \bullet 4 \mathrm{H}_{2} \mathrm{O}$ & & $5 \mathrm{mg}$ & \\
\hline $\mathrm{KH}_{2} \mathrm{PO}_{4}$ & $0,5 \mathrm{~g}$ & $0,5 \mathrm{~g}$ & \\
\hline $\mathrm{MgSO}_{4} \cdot 7 \mathrm{H}_{2} \mathrm{O}$ & $0,15 \mathrm{~g}$ & $0,5 \mathrm{~g}$ & \\
\hline $\mathrm{CaCl}_{2}$ & $0,05 \mathrm{~g}$ & $100 \mathrm{mg}$ & \\
\hline $\mathrm{FeCl}_{3}$ & $1,2 \mathrm{ml}$ (sol. 1\%) & & \\
\hline $\mathrm{NaCl}$ & $0,025 \mathrm{~g}$ & & \\
\hline \multicolumn{4}{|l|}{ Vitaminas } \\
\hline Tiamina $\mathrm{HCl}$ & $0,01 \mathrm{mg}$ & $0,05 \mathrm{mg}$ & \\
\hline Biotina & & $0,001 \mathrm{mg}$ & \\
\hline Ácido Fólico & & $0,1 \mathrm{mg}$ & \\
\hline Inositol & & $50 \mathrm{mg}$ & \\
\hline Agua Destilada & $1.000 \mathrm{ml}$ & $1.000 \mathrm{ml}$ & $1.000 \mathrm{ml}$ \\
\hline $\mathrm{pH}$ & 5,5 & 5,5 & 5,5 \\
\hline Agar & $15 \mathrm{~g}$ & $15 \mathrm{~g}$ & $15 \mathrm{~g}$ \\
\hline
\end{tabular}

Una vez realizadas las inoculaciones, las placas selladas y codificadas se colocaron en la cámara de crecimiento bajo oscuridad y a $23^{\circ} \mathrm{C}$ de temperatura. El ensayo evaluó los tres medios de cultivo anteriormente descritos y aplicados a cada cepa aislada, donde cada medio fue representado por tres repeticiones de una placa Petri cada una, totalizando 9 placas por cepa.

La evaluación del crecimiento de las cepas en los medios de cultivo se realizó después de 30 días de incubar las placas Petri en oscuridad a $23^{\circ} \mathrm{C}$. La evaluación del crecimiento consistió en medir con una regla el crecimiento radial de la cepa en cuatro direcciones, tomando como punto 0 , el centro de la placa conteniendo el medio de cultivo y el inóculo, registrando en cada ocasión el incremento en milímetros de la expansión del micelio desde el inóculo en su plano horizontal, sobre cada uno de estos ejes. 
Una vez realizada cada medición, a cada una de ellas se le restó el radio del círculo puesto inicialmente, para obtener finalmente el crecimiento real. Los datos obtenidos fueron digitados y depurados, para posteriormente realizar los análisis de varianza y comparación múltiple de medias (Test de Duncan con alfa $=0,05$ ) utilizando el software estadístico InfoStat, versión 2011/P.

\section{RESULTADOS}

\section{Prospección y Colecta de Hongos Comestibles}

Como resultado del trabajo de prospección y colecta (Figura $\mathrm{N}^{\circ} 3$ ), se realizaron 92 colecta de especímenes, a los cuales se le realizaron los trabajos de aislación y limpieza de contaminaciones en el laboratorio de INFOR en Concepción.

Sin embargo, del total colectado, se lograron aislar en forma definitiva un total de 75 cepas, 52 de ellas correspondieron a cepas de especies de hongo comestibles con las cuales se trabajó para el montaje de los experimentos.

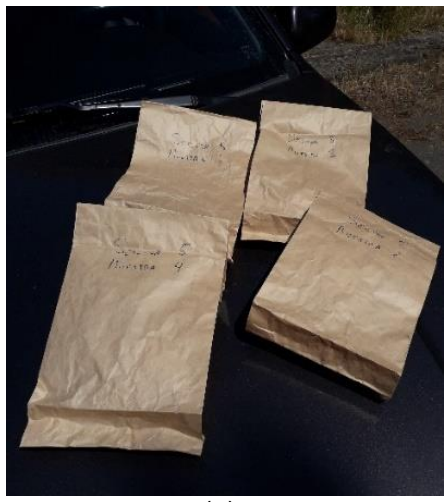

(a)

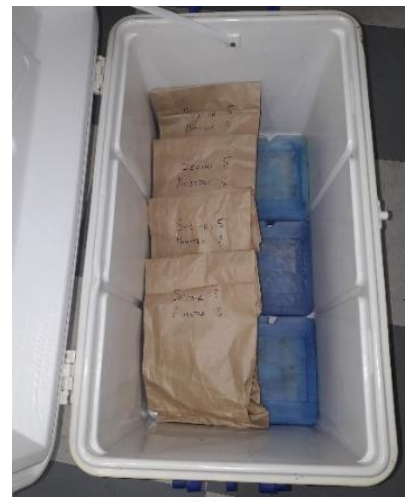

(b)

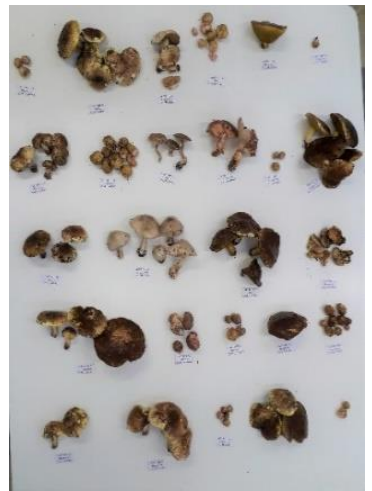

(c)

(a) Muestras en bolsas de papel con código para identificación del sitio

(b) Contenedor con icepack para mantener muestras a $3-4^{\circ} \mathrm{C}$

(c) Ordenación y codificación de muestras en laboratorio

Figura $\mathrm{N}^{\circ} 3$

COLECTA DE HONGOS

\section{Aislación de Cepas}

La respuesta de las cepas a la metodología de aislación utilizada fue variable, observándose crecimientos muy lentos como fue el caso de algunas cepas de Butyriboletus loyo y Volvariella speciosa. Otras en cambio, respondieron muy bien a algún tipo de medio o a todos ellos sin distinción como es el caso de las cepas de Grifola gargal. 
Se observó durante el proceso de aislación contaminación de algunos tejidos aislados dentro de los cultivos, lo que generó un inmediato proceso de sub cultivos para la eliminación de la contaminación respectiva, lográndose una eliminación exitosa en la mayoría de los tejidos de las cepas aisladas, después de unos meses de trabajo.

En otros casos la cepa no pudo ser separada del organismo contaminante, por lo que varias cepas en proceso de aislación se perdieron (Figura $\mathrm{N}^{\circ} 4$ ).
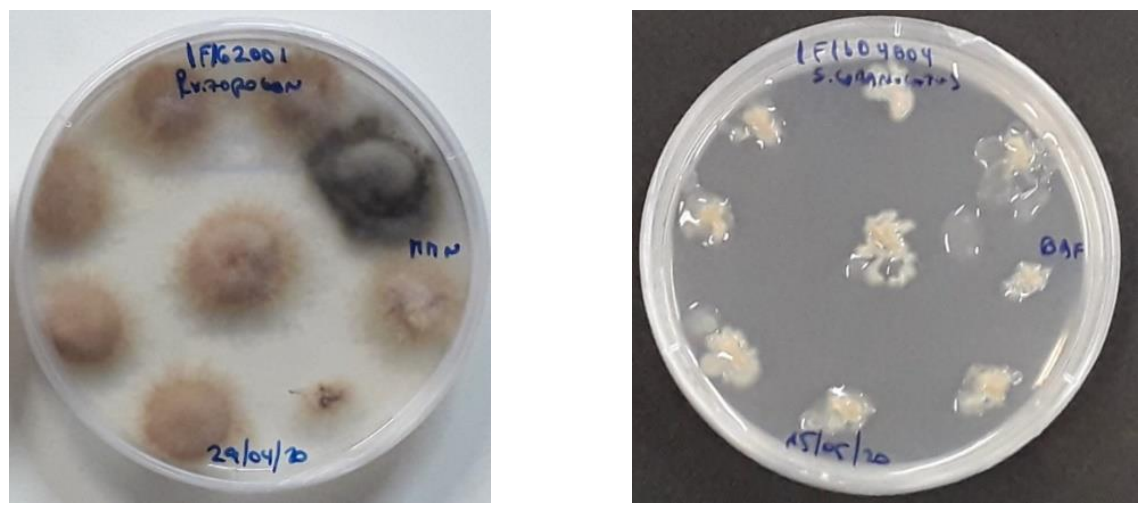

Figura $\mathrm{N}^{\circ} 4$

CONTAMINACIÓN POR BACTERIAS Y HONGOS

\section{Selección de Medios de Cultivo}

Una vez realizada la instalación de los ensayos con las 52 cepas de hongos comestibles, se procedió a realizar las mediciones una vez cumplido el período de 30 días, tiempo suficiente para que la cepa desarrollara crecimiento (Figura $\mathrm{N}^{\circ} 5$ ).

Los resultados de las mediciones con los crecimientos promedios de cada una de las cepas en cada uno de los medios, junto con los resultados de los análisis estadísticos respectivos se muestran en el Cuadro $\mathrm{N}^{\circ} 3$. Para los análisis de varianza y comparación múltiple de medias (Test de Duncan con alfa = 0,05) utilizando el software estadístico InfoStat, versión 2011/P.

En lo que respecta a la especie Suillus luteus, existe un comportamiento variable de acuerdo a la 13 cepas que se analizaron. La gran mayoría de las cepas presentaron un crecimiento mayor en los 2 medios más complejos, sin embargo, cinco de ellas no presentan diferencias significativas en el crecimiento radial entre los medios de cultivo utilizados, en tanto que otras 6 presentan crecimientos con diferencias estadísticamente similares entre los medios BAF y MMN, pero que difieren en el nivel de significancia en relación al medio PDA. Mientras que otras 2 cepas presentan diferencias significativas entre el medio BAF y los otros medios evaluados. Estos resultados concuerdan con los obtenidos por Pereira et al. (2007) y Chávez et al. (2007), los cuales encontraron un crecimiento eficiente en los medios MMN y BAF en valores de $\mathrm{pH}$ entre 4,8 y 5,8. 


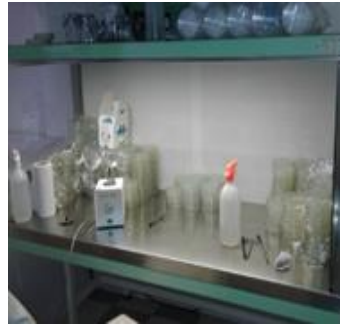

(a)

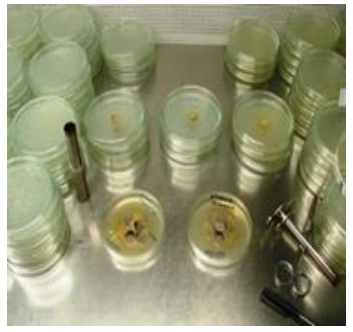

(d)

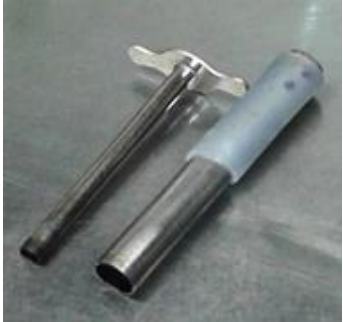

(b)

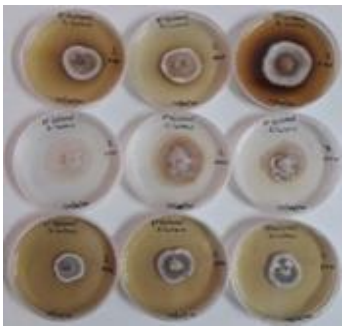

(e)

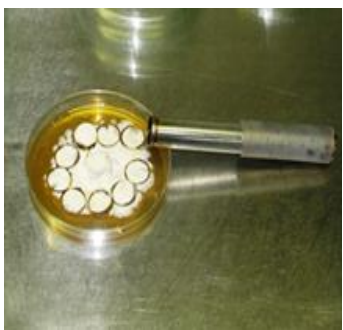

(c)

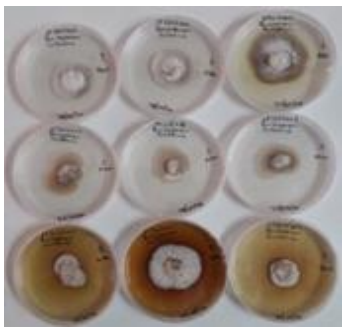

(f)

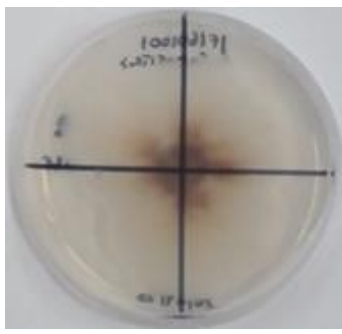

(g)

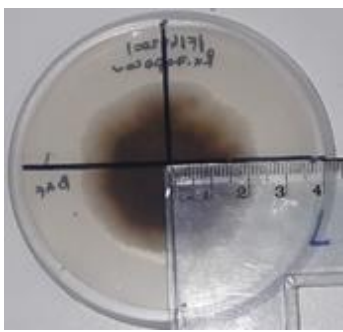

(h)

(a) Instalación de ensayos bajo ambiente estéril en cámara de flujo laminar

(b) Sacabocados de acero para la elaboración de discos de micelio

(c) Elaboración de discos de inoculación

(d) Aspecto de los discos de micelio puesto en los medios de cultivo en placas de Petri

(e) Crecimiento radial de Suillus luteus (cepa IF1613005) en medios PDA, MMN y BAF

a los 30 días

(f) Crecimiento radial de Rhizopogon luteolus (cepa IF1615003) en medios PDA, MMN y BAF a los 30 días

(g) Marcaje de líneas de puntos de medición

(h) Medición de crecimiento radial

Figura $N^{\circ} 4$

INSTALACIÓN DE ENSAYO Y AISLACIÓN DE CEPAS 
Los resultados muestran también concordancia con estudios realizados por Gonzalez et al. (2014), quienes concluyen que esta especie se desarrolla adecuadamente en los medios BAF y MMN, con una abundancia de nutrientes, como también en un medio como EMA con baja presencia de ellos. Además, estos mismos investigadores señalan que las cepas de esta especie son determinantes en el tipo de respuestas al crecimiento en condiciones in vitro. Las diferencias en relación al origen de las cepas también fueron observadas en otros estudios realizados en España por Ruiz-Diez et al. (2006) que indican una diferencia en el crecimiento de los cultivos dependiendo de la zona de procedencias de las cepas

En relación a Suillus granulatus, los ensayos realizados indican que los mejores crecimientos a los 30 días de evaluados correspondieron al medio BAF, pero siendo las cepas IF1616002 y IF18001, las que muestran diferencias significativas tanto para el medio PDA como para MMN en relación a la primera y solo PDA para la segunda, observándose además que las otras 5 cepas de $S$. granulatus presentaban la misma tendencia de crecimiento, aunque sin presentar diferencias entre los medios. Estos resultados difieren en cuanto a lo obtenido por experiencias realizadas por Murrieta et al. (2013) trabajando con una cepa de esta especie, logrando como resultado una mayor área de crecimiento bajo el medio PDA.

Suillus bellini representado en el ensayo por tres cepas, mostró crecimientos mayores en medios más complejos, sin embargo, solo la cepa IF1611003 presentó diferencias significativas entre los tres medios, con un crecimiento mayor en el medio MMN.

Como resultado de la respuesta a los medios de crecimiento para las 3 especies del género Suillus, se observa una tendencia similar en relación a un mayor crecimiento radial en medios más complejos. Esta similitud en el comportamiento fue en parte demostrada por estudios realizados por Pereira et al. (2007), quienes encontraron un comportamiento en crecimiento en medio BAF similar entre $S$. bellini y $S$. luteus.

Para el caso de Agaricus campestris, este presentó un crecimiento mucho más lento que especies saprófitas como Pleurotus ostreatus o Flammulina velutipes. De los crecimientos obtenidos, los mejores resultados se lograron con el medio BAF seguido de PDA. Según estudios realizados por Pacioni (1987) con la especie A. bisporus, los mejores resultados se obtuvieron con los medios PDA (Papa-dextrosa-agar), MEA (Extracto de malta-agar) y MPGA (Malta-peptonaagar).

Para el presente estudio el medio más completo en nutrientes y vitaminas fue el que alcanzó mayor expansión en las placas, siendo estadísticamente significativo su crecimiento en relación a PDA y MMN, este último con un resultado significativamente menor en relación a los otros medios evaluados. En tanto que, para la especie del mismo género, $A$. arvensis las dos cepas evaluadas presentan un comportamiento similar, con un crecimiento estadísticamente significativo, entre el medio BAF en relación a los otros medios evaluados.

Otra especie evaluada fue Rhizopogon luteolus, con 7 cepas evaluadas, de las cuales 5 no presentaron diferencias significativas entre los 3 medios aplicados, mientras que las otras 2 , las cepas IF1608001 y IF1612004, tuvieron un crecimiento estadísticamente significativo respecto a PDA y BAF o solo para PDA, respectivamente. En tanto que otros especímenes del género, pero no identificados aún a nivel de especie, mostraron también crecimientos mayores en el medio MMN pero solo la cepa IF1615004 presentaba diferencias significativas respecto a los otros medios de crecimiento evaluados. 
Cuadro $\mathrm{N}^{\circ} 3$

SELECCIÓN DE MEDIOS DE CULTIVO PARA CEPAS DE HONGOS COMESTIBLES COLECTADAS

\begin{tabular}{|c|c|c|c|c|c|c|c|c|}
\hline \multirow{2}{*}{$\mathrm{N}^{\circ}$ Cepa } & \multirow{2}{*}{ Especie } & \multirow{2}{*}{$\begin{array}{c}\mathrm{N}^{\circ} \\
\text { Repet. }\end{array}$} & \multicolumn{6}{|c|}{ Medios de Cultivo $(\mathrm{cm})$} \\
\hline & & & PDA & $*$ & MMN & * & BAF & $*$ \\
\hline IF1601001 & Agaricus campestris (L.) Fr. & 3 & 0,86 & $\mathrm{~b}$ & 0,50 & $\mathrm{a}$ & 1,08 & c \\
\hline IF1601005 & Volvariella speciosa (Fr.) Sing. & 3 & 1,12 & a & 0,78 & a & 1,16 & a \\
\hline IF1602001 & Rhizopogon luteolus Fr. & 3 & 0,70 & a & 0,72 & a & 0,81 & a \\
\hline IF 1602004 & Agaricus arvensis Schaeff. & 3 & 0,71 & $b$ & 0,40 & a & 1,23 & c \\
\hline IF1603001 & Suillus luteus (L.) Roussel & 3 & 0,75 & a & 1,19 & $b$ & 1,08 & $b$ \\
\hline IF1603004 & Suillus granulatus (L.) Kuntze & 3 & 1,15 & a & 1,05 & a & 1,58 & a \\
\hline IF1603007 & Agaricus arvensis Schaeff. & 3 & 0,96 & a & 0,95 & a & 1,18 & $b$ \\
\hline IF1604001 & Flammulina vellutipes (Kurt.:F.) Karst & 3 & 3,50 & a & 3,39 & a & 3,50 & a \\
\hline IF 1604002 & Lactarius deliciosus (L.:Fr.) Gray & 3 & 0,65 & $\mathrm{~b}$ & 0,27 & a & 1,43 & c \\
\hline IF1605002 & Suillus granulatus (L.) Kuntze & 3 & 0,92 & a & 0,91 & a & 1,17 & a \\
\hline IF 1606005 & Suillus luteus (L.) Roussel & 3 & 0,69 & a & 1,45 & $b$ & 1,38 & b \\
\hline IF1607001 & Suillus luteus (L.) Roussel & 3 & 0,78 & a & 0,91 & a & 0,87 & a \\
\hline IF 1608001 & Rhizopogon luteolus Fr. & 3 & 0,73 & a & 1,24 & $b$ & 0,85 & a \\
\hline IF1608003 & Pleurotus ostreatus (Jacq.) P. Kumm. & 3 & 0,49 & a & 1,68 & b & 2,73 & c \\
\hline IF1608006 & Lactarius deliciosus (L.:Fr.) Gray & 3 & 0,83 & a & 0,38 & a & 0,83 & a \\
\hline IF1609003 & Suillus luteus (L.) Roussel & 3 & 1,05 & a & 1,08 & a & 1,79 & $b$ \\
\hline IF 1610002 & Suillus luteus (L.) Roussel & 3 & 0,46 & a & 0,81 & $a b$ & 0,96 & b \\
\hline IF1611002 & Rhizopogon luteolus Fr. & 3 & 0,58 & a & 1,03 & a & 1,23 & a \\
\hline IF 1611003 & Suillus bellini (Inz.) Kuntze & 3 & 0,64 & a & 1,42 & c & 1,09 & $\mathrm{~b}$ \\
\hline IF1615002 & Suillus granulatus (L.) Kuntze & 3 & 0,92 & a & 0,83 & a & 1,15 & a \\
\hline IF 1615003 & Rhizopogon luteolus Fr. & 3 & 0,72 & a & 0,93 & a & 0,91 & a \\
\hline IF1615004 & Rhizopogon sp. & 3 & 0,71 & a & 1,04 & $b$ & 0,67 & a \\
\hline IF 1615005 & Rhizopogon sp & 3 & 0,98 & a & 1,58 & a & 1,09 & a \\
\hline IF1616001 & Boletus loyo Philippi. & 3 & 0,17 & a & 0,14 & a & 0,18 & a \\
\hline IF1616002 & Suillus granulatus (L.) Kuntze & 3 & 0,58 & a & 0,86 & $b$ & 1,32 & c \\
\hline IF 1616004 & Lactarius deliciosus (L.:Fr.) Gray & 3 & 0,98 & a & 0,51 & a & 0,92 & a \\
\hline IF1616008 & Suillus luteus (L.) Roussel & 3 & 1,39 & a & 1,73 & $b$ & 1,66 & $a b$ \\
\hline IF1617002 & Suillus luteus (L.) Roussel & 3 & 0,61 & a & 1,14 & a & 1,26 & a \\
\hline IF1618001 & Suillus granulatus (L.) Kuntze & 3 & 1,28 & a & 1,64 & $a b$ & 1,88 & b \\
\hline IF1618002 & Suillus luteus (L.) Roussel & 3 & 1,56 & a & 1,24 & a & 1,63 & a \\
\hline IF 1619001 & Suillus luteus (L.) Roussel & 3 & 1,17 & a & 1,61 & a & 1,43 & a \\
\hline IF1619003 & Suillus bellini (Inz.) Kuntze & 3 & 0,83 & a & 0,93 & a & 0,90 & a \\
\hline IF 1620001 & Morchella esculenta (L.) Pers. & 3 & 0,64 & a & 0,48 & a & 2,87 & $b$ \\
\hline IF1620002 & Morchella elata Fr. & 3 & 1,56 & $b$ & 0,63 & a & 3,85 & c \\
\hline IF1620003 & Morchella conica Pers. & 3 & 2,68 & $b$ & 0,15 & $\mathrm{a}$ & 3,85 & c \\
\hline IF1621001 & Morchella sp & 3 & 1,78 & $b$ & 0,33 & a & 3,85 & c \\
\hline IF1621003 & Suillus luteus (L.) Roussel & 3 & 1,02 & a & 1,08 & a & 1,27 & $\mathrm{~b}$ \\
\hline IF1622001 & Flammulina vellutipes (Kurt.:F.) Karst & 3 & 4,2 & a & 4,2 & a & 4,2 & a \\
\hline IF1622002 & Agrocybe aegerita (V. Brig.) Sing, & 3 & 4,2 & a & 4,2 & a & 4,2 & a \\
\hline
\end{tabular}

Nota: * Test de Duncan Alfa=0,05

Medias con una letra común en la misma fila no son significativamente diferentes $(p>0,05)$ 
En relación a la especie Volvariella speciosa, con la cepa IF1601005 presentó crecimiento mayores y casi similares entre el medio BAF y PDA, siendo el medio MMN el que produjo un menor crecimiento. Sin embargo, estadísticamente estos tres medios no presentaron diferencias significativas entre ellos. Respecto al crecimiento, se deberán seguir las investigaciones en torno a mejorar las condiciones medio ambientales para un mejor desarrollo del micelio. En ese sentido Fasidi y Akwakwa (1996) han avanzado en utilizar ciertas fuentes de carbohidratos, fuente de nitrógeno y una proporción $\mathrm{C} / \mathrm{N}$ adecuada que impactarían positivamente el crecimiento miceliar.

Por su parte, Lactarius deliciosus mostró un crecimiento bastante menor en el medio MMN para las 4 cepas, sin embargo, solo 2 de estas presentan crecimientos mayores en el medio de cultivo BAF, estableciéndose diferencias significativas con MMN y PDA para las cepas IF1615001 y IF1604002. En tanto la cepa IF1604003, identificada solo a nivel de género, presenta también diferencias estadísticamente significativas entre el medio BAF respecto a los medios MMN y PDA. En relación a estos resultados, lotti et al. (2012), mencionaron que Lactarius spp se mantienen de forma normal en los medios más comunes informados por diferentes investigadores, como agar papa dextrosa (PDA), agar biotina-aneurina-ácido fólico (BAF), agar extracto de malta (MEA) y agar Melin-Norkrans modificado (MMN).

La especie nativa Butyriboletus loyo presentó en los tres medios utilizados, poco desarrollo miceliar debido a su lento crecimiento, reaccionando de igual manera para los 3 medios, pero sin un crecimiento que definiera diferencias significativas entre ellos. Comportamiento similar es el reportado por Chung (2016), indicando que en los ensayos realizados en diferentes medios de cultivo se obtuvo a los 30 días para esta especie un lento crecimiento que fluctuó entre 0,1 a 0,2 $\mathrm{cm}$ a los 30 días.

Las especies Morchella sp., M. esculenta, M.conica y M, elata presentaron los mayores crecimientos miceliares en el medio más rico en nutrientes como es el medio BAF con diferencias significativas en todas las cepas ensayadas de este género en relación a los otros medios de cultivo evaluados. A su vez, de los medios de menor crecimiento, el de más bajo desarrollo correspondió a medio MMN. Respecto a los resultados obtenidos, estudios citados por Alvarado et al. (2008) y realizados por Volk, Buscott, Stott entre otros varios investigadores, señalaron que el crecimiento miceliar para el caso de $M$. esculenta es bastante rápido y la disminución de medios nutricionales es un factor que aminora su crecimiento. De las observaciones realizadas al crecimiento miceliar, se verificó la formación de esclerocios en el medio BAF, el cual presentaba las mejores condiciones nutricionales. Este fenómeno es comentado por Alvarado et al. (2008), quienes señalan que no es necesaria una condición de restricción para la aparición de dichas estructuras.

Respecto de Armillaria mellea, hongo parásito de tipo cosmopolita, su desarrollo fue acompañado por una serie de ramificaciones (rizomorfos), siendo estos de mayor número en el medio PDA, y asociado también a un crecimiento miceliar mucho mayor a los medios MMN y BAF.

En relación a la especie saprófita nativa Grifola gargal, esta presentó un crecimiento mayor en los medios de cultivo más complejo, siendo el medio de crecimiento MMN, el que generó mayor crecimiento promedio y presentando diferencias significativas con el medio PDA, pero no así con el medio BAF, el cual no presento diferencias con el medio PDA. De acuerdo a Postemsky et al. (2006), la determinación óptima para la producción de micelio de G. gargal es un paso fundamental para la producción optimizada de algunos de sus constituyentes con potencial nutricional y valor nutritivo y farmacológico.

Para la especie Agrocybe aegerita, el desarrollo miceliar fue bastante rápido, cubriendo 
rápidamente las placas de los tres medios evaluados, por lo que estos no fueron de importancia para el buen crecimiento de la cepa evaluada.

En el caso de Pleurotus ostreatus, la cepa evaluada tuvo un crecimiento bastante lento, donde predominó un crecimiento cada vez mayor a medida que se complejizaba el medio de cultivo, obteniéndose el mayor crecimiento en el medio BAF.

Por último, las 2 cepas de la especie Flammulina velutipes, desarrollaron un crecimiento bastante rápido, logrando para la cepa IF1622001 crecer en todas las placas Petri en el máximo de su capacidad en menos de 30 días, por lo que los medios evaluados fueron indiferentes al ritmo de crecimiento de esta cepa. Mientras que la cepa IF1604001 también presentó un ritmo de crecimiento bastante rápido e indistintamente del medio en el que se desarrollaba, sin embargo, luego de 30 días de crecimiento, no llegó a cubrir en su totalidad las placas

\section{CONCLUSIONES}

De los crecimientos medios obtenidos de cada cepa y en cada medio evaluado, se concluye que no existe un medio común que pueda ser el más eficaz en obtener el mayor crecimiento para una especie fúngica, demostrándose que existen comportamientos diferentes entre las especies y dentro de cada una de ellas (cepas), lo cual se ve reflejado en los resultados obtenidos.

El conocimiento más acabado del comportamiento de los hongos y de sus diferentes cepas en medios de cultivo específicos, requerirá de mayores estudios para definir medios en particular para cepas específicas, buscando precisar no solo el medio preciso para su crecimiento, sino que, además, sus requerimientos climáticos.

En los resultados obtenidos en el crecimiento de las distintas especies y cepas, no se descarta el efecto de parámetros medio ambientales, como el pH que pudiera haber influido en los resultados logrados en relación a su desarrollo miceliar. Para los ensayos establecidos el pH de 5,5 fue estándar para los tres medios de cultivo, lo cual pudo haber influido en el desempeño de las cepas. Esto fue mencionado por Pereira et al. (2007), cuyos experimentos con distintas especies de hongos micorrícicos indicaron que una variación de $\mathrm{pH}$ es determinante en el comportamiento de las especies de hongos micorrícicos in vitro.

Por lo tanto, es importante proseguir los estudios que permitan determinar las condiciones óptimas de cultivo, relacionando parámetros como el $\mathrm{pH}$, la temperatura y la composición del medio de crecimientos más adecuados para cada especie y cepa de interés. Respecto al medio de cultivo, lotti et al. (2012) reafirman la especificidad de estos para cada especie, afirmando que muchos hongos ectomicorrícicos se pueden cultivar en medios de cultivo sintéticos y semisintéticos, pero la tasa de crecimiento es extremadamente variable debido a requerimientos propios de cada especie.

En tanto que, Pereira et al. (2007) observaron que el mejor comportamiento que presentan los hongos cultivados in vitro se produce en medios nutritivos cuyo $\mathrm{pH}$ es similar a aquel registrado en los suelos en donde estos estaban creciendo en forma natural, por lo que las condiciones de $\mathrm{pH}$ del sector de colecta del material fúngico deben ser consideradas para optimizar el cultivo y propagación de los hongos en laboratorio.

En lo relativo a los trabajos de colecta de material fúngico, el efecto de factores de tipo climático y biológico fueron elementos que influyeron en estas labores, siendo las precipitaciones, 
uno de los parámetros ambientales más importantes junto a la temperatura, las que marcaron las fechas de aparición, pero siempre muy ligados a los ciclos biológico de la especie o a sus propios requerimientos ecológicos. Un ejemplo de ello es Butyriboletus loyo, hongo micorrícico gregario, que aparece con las primeras lluvias abundantes de fines de verano y comienzos de otoño; o de Grifola gargal, hongo saprófito, con fructificaciones bastante escasas y que aparecen luego de abundantes precipitaciones en otoño. Estos comportamientos propios de cada especie dificultaron en cierta forma los trabajos de recolección,

Como resumen de los trabajos de recolección de especímenes fúngicos, se logró colectar 92 cepas para la región de Ñuble, 75 de las cuales fueron aisladas y de ellas, 52 correspondieron a cepas de hongos comestibles, sobre las cuales se realizaron los ensayos correspondientes.

Con respecto al material fúngico recolectado, se cuenta para la región de Ñuble con cepas de diversas especies fúngicas comestibles de interés, dentro de los cuales, se cuentan las especies Suillus luteus, S. granulatus, S. bellini, Lactarius deliciosus, Rhizopogon luteolus, para hongos comestibles del bosque de pino; además de Grifola gargal, Butyriboletus loyo, Morchella esculenta, $M$. conica, $M$. elata en Bosque nativo. Además, se aislaron cepas de las especies Volvariella speciosa, Agaricus campestris, A.arvensis, Flammulina velutipes, con presencia en pastizales fuera y dentro del bosque y con comportamiento saprofito; al igual que Cyclocibe aegerita y Pleurotus ostretus, pero con hábitos de tipo lignícola; y finalmente, Armillaria mellea, hongo parásito con cuerpos fructíferos comestibles llamados "pique".

\section{REFERENCIAS}

Alvarado, G; Mata, G.; Nava, M.; Martínez, D. y Platas, D., 2008. Obtención de esclerocios de morilla (Morchella esculenta) en diferentes medios de cultivo. Interciencia, Vol. 33, N7, Pp: 528-531

Boa, E., 2005. Productos Forestales No Madereros 17. Los hongos silvestres comestibles. Perspectiva global de su uso e importancia para la población. FAO, Roma. 163 pp.

Catalán, R., 2006. La otra oferta de los árboles nativos: No sólo madera da el bosque. Coordinador del Programa de Conservación con Comunidades de la oficina en Chile del Fondo Mundial para la Vida Silvestre (WWF). [en línea] <http://www.lignum.cl/noticias/imprimir_noticia.php?id=8046> [Consulta :13 de diciembre 2006].

Chávez, D.; Pereira, G. y Machuca, A., 2007. Crecimiento in vitro de cuatro especies de hongos ectomicorrícicos recolectados en plantaciones de Pinus radiata. Agrociencia 23: 79-84.

Chung, P., 2016. Desarrollo de banco de hongos comestibles Instituto Forestal. Ciencia e Investigación Forestal, Vol. 22. $\mathrm{N}^{\circ} 3$, pp: 7-41.

CONAF, 2015. Catastro de los Recursos Vegetacionales Nativos de Chile. Corporación Nacional Forestal

INFOR, 2004. Innovación Tecnológica y Comercial de Productos Forestales No Madereros (PFNM) en Chile. Instituto Forestal, Chile. [en línea] < http://www.gestionforestal.cl/pfnm/index. htm>. [Consulta :13 de abril 2020].

INFOR, 2019. Programa de Actualización Permanente de Plantaciones Forestales. Instituto Forestal, Chile.

FAO, 2008. Restableciendo el equilibrio: las mujeres y los recursos forestales. Producido por el departamento de Montes, disponible en http://www.fao.org/ DOCREP/x00225.hmt. 21/02/08.

Fasidi, I. y Akwakwa, D., 1996. Growth requirements of Volvariella speciosa (Fr. ex. Fr.) Sing., a Nigerian mushroom. Food Chemistry.Vol.55, Num. 2, Pag: 165-168

Iotti, M.; Piattoni, F. y Zambonelli, A., 2012. Techniques for Host plant Inoculation with Truffles and other edible ectomycorrhizal mushrooms.. A. Zambonelli and G.M. Bonito (eds.), Edible Ectomycorrhizal Mushrooms, Soil 
González, M.; Quiroz, I.; Travieso, R.; Chung, P. y García, E., 2014. Determinación de medios de cultivo y pH para la masificación in vitro de cepas de Suillus luteus Aubl. asociadas a Pinus radiata D. Don y Scleroderma citrinum Pers. asociadas a Eucalyptus globulus Labill. de la Región del Bio Bío, Chile. Revista Árvore, Viçosa-MG, v.39, n.1, p.105-113.

Honrubia, M., 2011. Los hongos silvestres como fuente de desarrollo local. En: Libro de Resúmenes. Simposio Internacional Gestión Forestal del Recurso Micológico. Valladolid. Castilla y León (ESPAÑA). 9-11 de Junio.

Marx, D. H., 1969. The influence of ectotrophic fungi on the resistance of Pine roots to pathogenic infections. I. Antagonism of mycorrhizal fungi to root pathogenic fungi and soil bacteria. Phytopathology, v.59, p.153-163.

Moser, M., 1960. Die Gattung Phlegmacium. Die Pilze Mitteleupora's 4. J. Bad Heilbrunn.

Murrieta, D; Noa, J; Mata, M; Pineda, M; Zulueta, R y Flores, N., 2013. Effect of culture medium on development of Suillus granulatus (L.) Roussel and S. brevipes (Pk.) Kuntze. Revista Chapingo Serie Ciencias Forestales y del Ambiente Pp: 29-35. doi: 10.5154/r.rchscfa.2013.06.021. http://www.chapingo.mx/revistas Pacioni, G., 1987. El cultivo moderno del champiñón. España. Editorial De Vecchi. 73 p.

Pereira, G.; Herrera, J.;. Machuca, A. y Sánchez, M., 2007. Efecto del pH sobre el crecimiento in vitro de hongos ectomicorrícicos recolectados de plantaciones de Pinus radiata. Bosque 28: 215-219.

Peters, C., 1996. The ecology and management of non timber forest resources. World Bank Technical. Paper 322. Washington, D.C., USA. 157 p.

Postemsky, P.; González, R.; Figlas, D. y Curvetto, N., 2006. Optimizing Grifola sordulenta and Grifola gargal growth in agar and liquid nutrient media. Micología Aplicada Internacional. 18(1):7-12.

Rodríguez, G.; Zapata, E; Rodríguez, M; Vázquez, V; Martínez, B. and Vizcarra, I., 2012. Traditional knowledge, access, use and transformation of wild edible fungi in Santa Catarina del Monte, Estado de México. Agricultura, Sociedad y Desarrollo. Vol. 9, N²: 191-207.

Ruiz-Diez, B; Rincón, A; De Felipe, M. y Fernández-Pascual, M., 2006. Molecular characterization and evaluation of mycorrhizal capacity of Suillus isolates from central Spain for the selection of fungal inoculants. Mycorrhiza 16: 465-474.

Saavedra, J., 2004. Análisis del proceso de comercialización de semillas forestales y ornamentales en dos centros de semillas. Memoria para optar al título de Ingeniero Forestal. Universidad De Chile, Facultad de Ciencias Forestales, Escuela de Ciencias Forestales, Departamento de Manejo de Recursos Forestales. 104 p.

Santiago-Martínez, G.; Estrada-Torres, A.; Varela, L. y Herrera, T., 2003. Crecimiento en siete medios nutritivos y síntesis in vitro de una cepa de Laccaria bicolor. Agrociencia, v.37, n.6, p.575-584.

Tacón, A. y Palma, J., 2005. Productos Forestales no Madereros. En: Bosques y comunidades del sur de Chile. Editado por Catalán, R; Wilken, P; Kandzior, A.; Tecklin, A. y H. Burschel. Editorial Universitaria, Chile. Pp: 253266.

Taller de Acción Cultural, 2003. Recolectoras de frutos silvestres. Oficio de mujeres en la Región del Biobío. Santiago de Chile. Serie de Derechos Laborales. 135 p.

Valenzuela, E., 2003. Hongos comestibles silvestres colectados en la X Región de Chile. Boletín Micológico Vol. 18: $1-14$ 


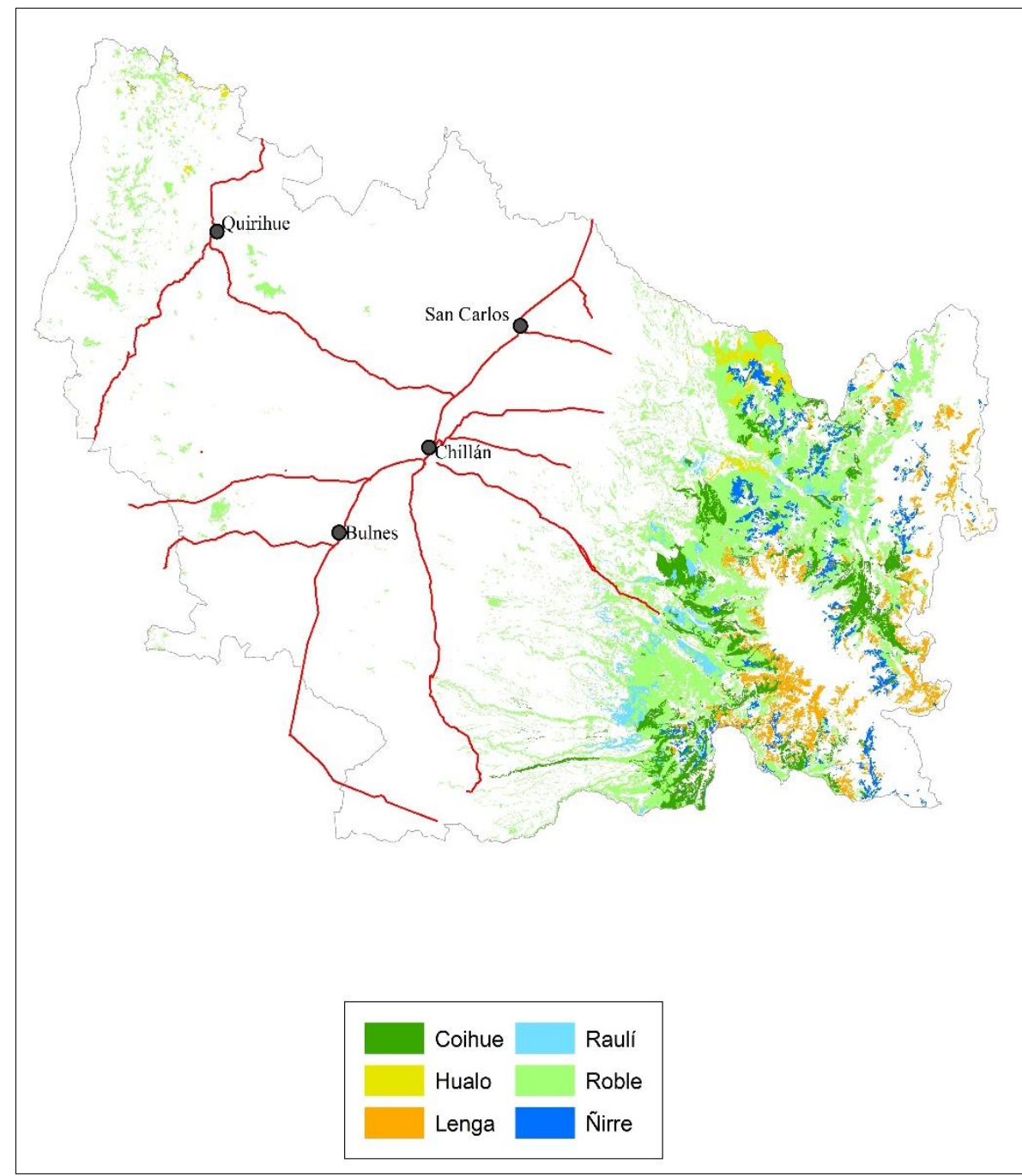

Mapa de la Región de Ñuble con Masas Forestales de las Especies del Género Nothofagus 


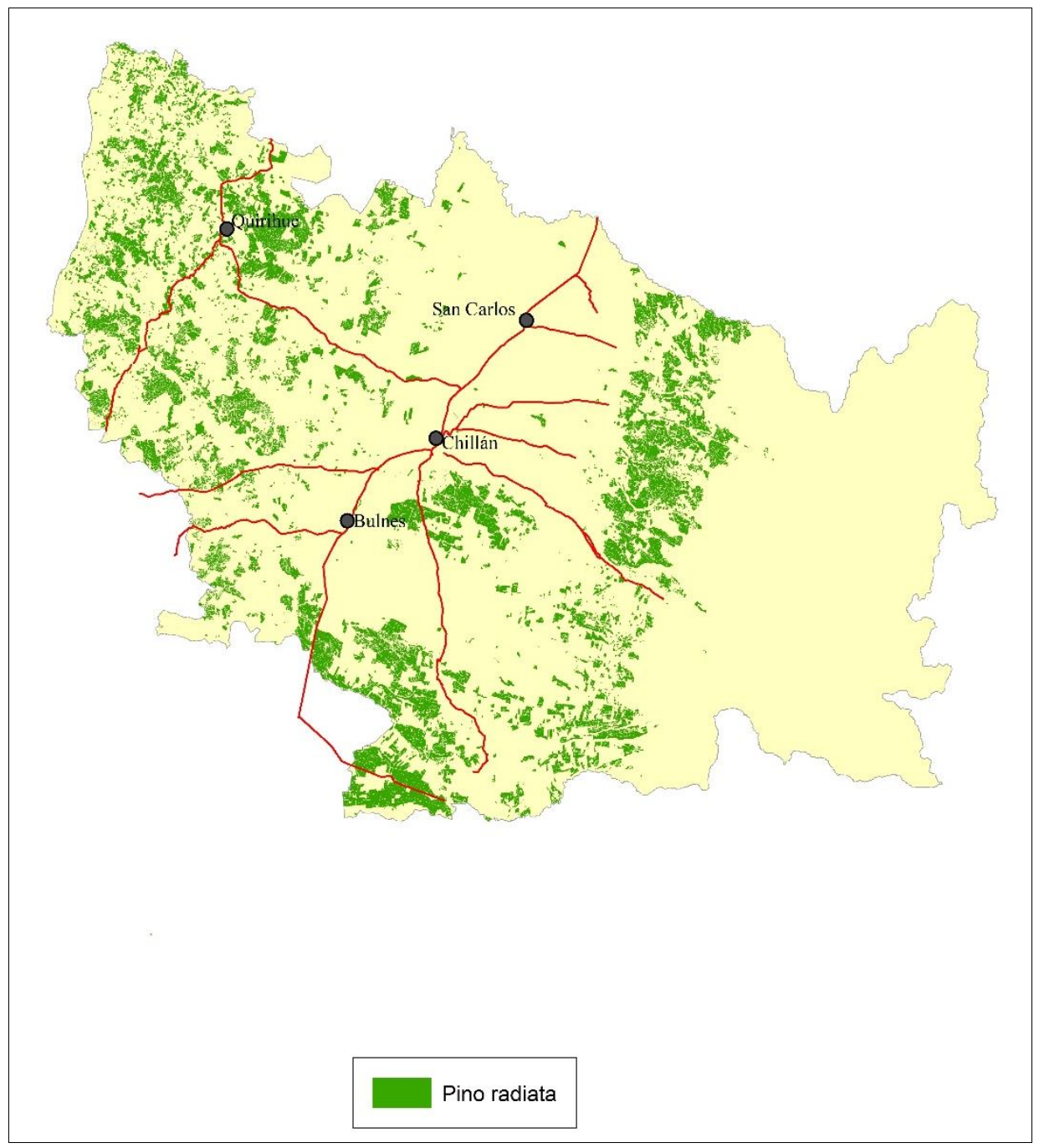

Mapa de la Región de Ñuble con las Masas Forestales de la Especie Pinus radiata 


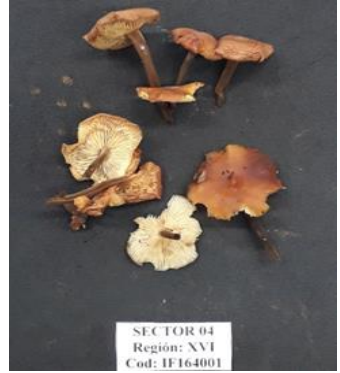

Especie: Flammulina vellutipes Código: IF164001

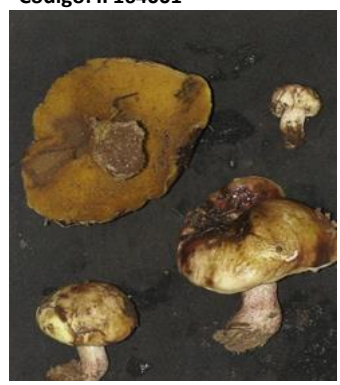

Especie: Suillus bellini Código: IF1619003

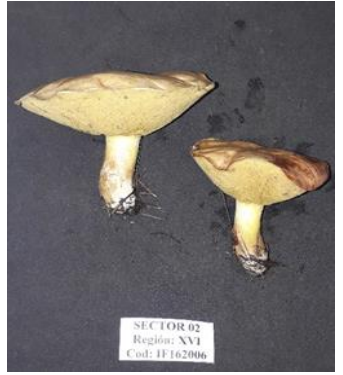

Especie: Suillus granulatus Código: IF162006

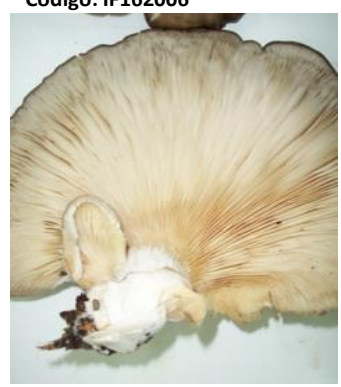

Especie: Pleurotus ostreatus Código: IF168003

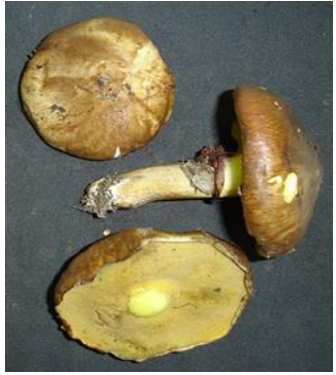

Especie: Suillus luteus Código: IF166005

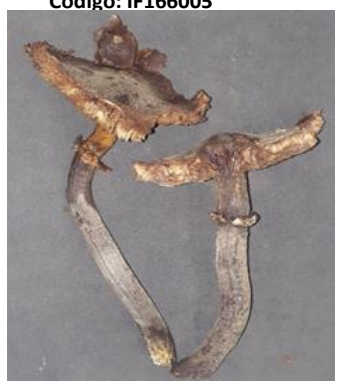

Especie: Armillaria mellea Código: IF164006 


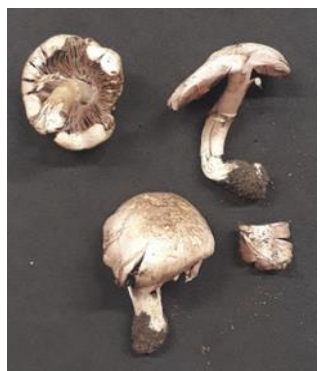

Especie: Agaricus campestris Código: IF161001

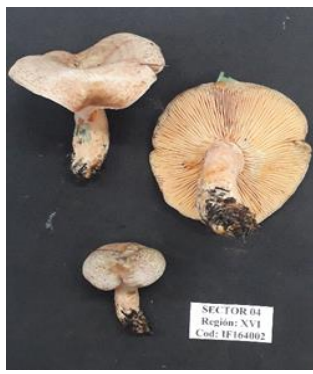

Especie: Lactarius deliciosus Código: IF164002

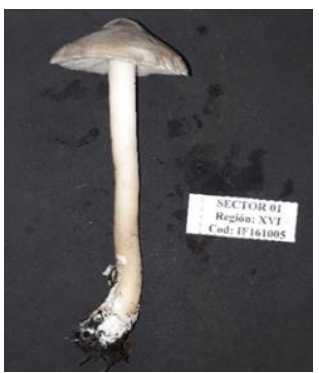

Especie: Volvariella speciosa Código: IF161005

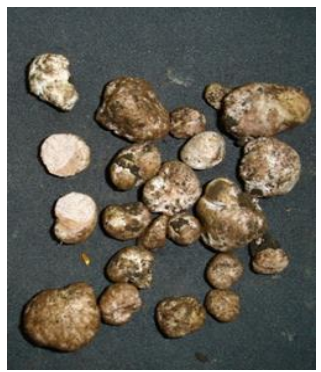

Especie: Rhizopogon luteolus Código: IF166002

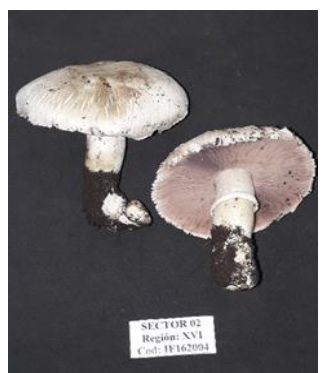

Especie: Agaricus arvensis Código: IF162004

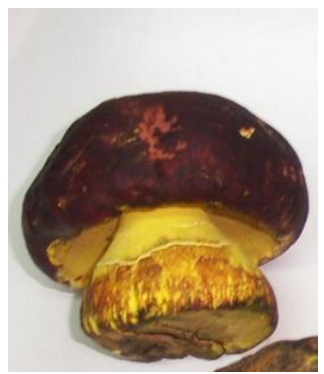

Especie: Butyriboletus loyo Código: IF16160 


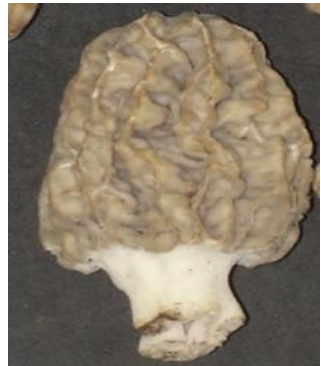

Especie: Morchella esculenta Código: IF1620001

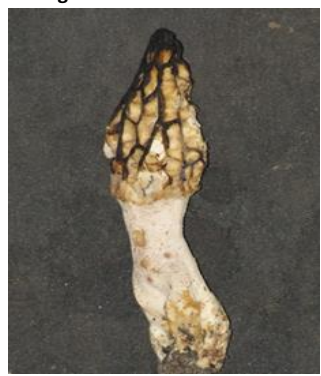

Especie: Morchella sp Código: IF1621001

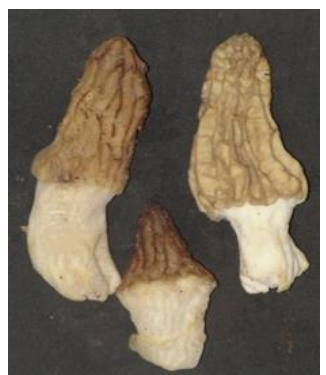

Especie: Morchella elata Código: IF1620002

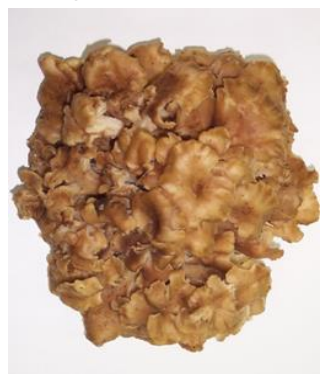

Especie: Grifola gargal Código: IF1623001

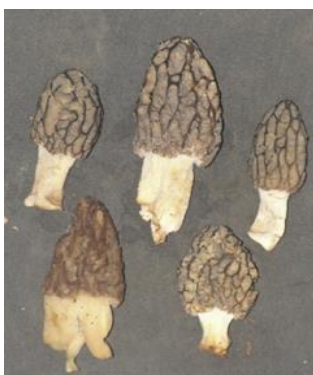

Especie: Morchella conica Código: IF1620003

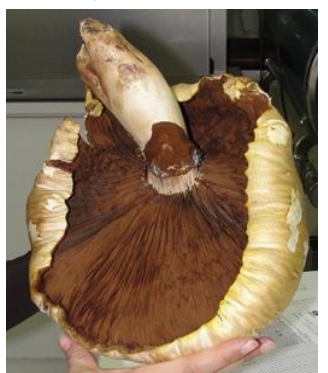

Especie Probable: Ciclocybe aegerita Código: IF1622002 